\title{
CPK: The new tool in the diagnosis of ectopic pregnancy
}

\author{
Suvarna Jyothi Ganta*, Sunanda R. Kulkarni, Vidya Muralidhar
}

Department of Obstetrics and Gynecology, Chinmaya Mission Hospital, Bangalore, Karnataka, India

Received: 31 March 2017

Accepted: 27 April 2017

\section{*Correspondence:}

Dr. Suvarna Jyothi Ganta,

E-mail: suvarnajyothi0705@gmail.com

Copyright: ( ) the author(s), publisher and licensee Medip Academy. This is an open-access article distributed under the terms of the Creative Commons Attribution Non-Commercial License, which permits unrestricted non-commercial use, distribution, and reproduction in any medium, provided the original work is properly cited.

\begin{abstract}
Background: Ectopic pregnancy is still a diagnostic dilemma presenting with various complaints. The classic triad of amenorrhea, abdominal pain, vaginal bleeding and /or syncope is not always seen. Misdiagnosis can lead to delay in treatment, blood loss is found to be the major cause of death. Early and accurate diagnosis is critical in bringing down the maternal mortality and morbidity. Prompt and effective treatment of an ectopic pregnancy can help preserve the chances of future healthy pregnancies. Aim of present study was to investigate whether creatinine phosphokinase (cpk) can be used as an effective diagnostic tool in the early diagnosis of ectopic pregnancy which can help in decreasing the maternal mortality and morbidity

Methods: This observational comparative three group clinical study was conducted at Chinmaya Mission Hospital, Bangalore, between May 2016 to January 2017.120 women in their early trimester were studied of which 40 were diagnosed cases of ectopic pregnancies, 40 women presented with intrauterine abortive pregnancies and 40 women had normal healthy pregnancies. Serum CPK, serum B-HCG, vaginal scans were done in all, along with routine investigations.

Results: The mean CPK values in normal, abortive and ectopic pregnancies were $36.92 \pm 6.44,43.95 \pm 11.96$ and $91.55 \pm 30.43$ respectively. It was found to be significantly higher in ectopic Pregnancies. Also, the mean CPK in ruptured and unruptured ectopic pregnancy were $97.26 \pm 25.97$ and $63.82 \pm 34.92$ respectively.

Conclusions: Present study shows that maternal CPK levels are significantly higher in women with ectopic pregnancies. CPK can serve as the reliable biochemical marker to diagnose ectopic pregnancy particularly ruptured. $\mathrm{CPK}$ can be used to increase the diagnostic efficacy in ectopic pregnancy, which followed by rapid and appropriate treatment can reduce the mortality, morbidity and preserve future fertility.
\end{abstract}

Keywords: Abortive pregnancy, B-hCG, CPK, Diagnostic tool, Ectopic pregnancy

\section{INTRODUCTION}

Ectopic or ECCYESIS - remains a dramatic obstetric emergency as well as a persistent diagnostic challenge. The word is derived from a Greek work "ektopos" meaning out of place. An ectopic pregnancy occurs when a fertilized egg implants somewhere other than the main cavity of the uterus. It is still the leading cause of pregnancy related maternal deaths in the first trimester. Incidence varies between 0.25-1percent of all pregnancies. In India, it is 3.12/1000 pregnancies. Recent increase in incidence is because of assisted reproductive, sterilization, pelvic infections, and IUCD usage. However, it's reassuring to know that despite the rising incidence, mortality and morbidity has been falling. ${ }^{1}$

Nearly $95 \%$ of these ectopics are implanted in various segments of the fallopian tube and remaining 5\% implant in the ovary, peritoneal cavity, cervix or previous caesarean scar. The commonest cause of a tubal 
pregnancy is tubal damage. Since the fallopian tube lacks a sub mucosal layer, the fertilized ovum promptly burrows through the epithelium into the muscularis by the rapidly proliferating trophoblast. ${ }^{2}$

Currently, the common methods in usage for diagnosing ectopic pregnancy are transvaginal ultrasound and serial $\beta$-hCG assays. Despite the use of high resolution transvaginal scans and sensitive assays for $\beta$-hCG, 40 to $50 \%$ of cases are initially missed. An inconclusive ultrasound with $\beta$-hCG below $1000 \mathrm{mIU} / \mathrm{dl}$ poses a diagnostic dilemma. This subgroup of patients in particular may benefit most from a serum marker that is accurate and rapidly available.

Research is directed towards early identification of ectopic pregnancy where successful medical management can dismiss the need for surgical intervention and subsequent salpingectomies. Tube conserving surgeries such as salpingotomy, salphingostomy and medical management with injection methotrexate are more successful when used in early pregnancy. They are likely to decrease the morbidity and long term sequalae associated with ectopic pregnancy. Thus, once again reiterating the importance of early diagnosis

The trophoblast eroding into the muscle layer causes damage and releases muscle cell products such as CPK into the circulation. CPK is an intracellular metabolic enzyme which catalyses adenosine triphosphate (ATP) production from creatine phosphate and Adenosine diphosphate(ADP) necessary for the contractile system. ${ }^{3}$

Lavie et al first brought CPK into limelight as a possible marker of smooth muscle damage in ectopic pregnancy (4). Since then many studies were undertaken some with total CPK and some others with isoenzymes like CPKMM and CPK-MB. Subsequently Chandra et al, Saha PK and others have confirmed CPK as a possible marker but Kurzel had differing results..$^{5-7}$

Early diagnosis is critical in bringing down the maternal mortality and morbidity. Ectopic pregnancy continues to be a diagnostic challenge to the obsteriticans, hence in our quest to find a marker we studied the role of CPK, which along with $\beta$-hCG and TVS can help us to clinch the diagnosis.

\section{METHODS}

This was an observational comparative three group clinical study, conducted in the department of Obstetrics and Gynecology of Chinmaya Mission Hospital, Bangalore between the May 2016 to January 2017. Women in the first trimester who presented to the emergency room with complaints of period of amenorrhea, vaginal bleeding, abdominal pain with or without syncope were enrolled for the study and followed up longitudinally. Study included 40 consecutive patients with documented tubal pregnancy, 40 consecutive women who had abortive intrauterine pregnancy (incomplete, threatened, missed abortion) and 40 normal healthy patients attending the antenatal clinic of the same hospital in the same period, who matched for age, parity and gestational period. The three groups were:

- $\quad$ ectopic pregnancy (EP),

- abortive pregnancy (AP) and

- $\quad$ normal intrauterine pregnancy (NP).

\section{Exclusion criteria}

- Women with a recent history of surgery,

- Major trauma, chest pain, neurological disease

- Hypothyroidism,

- Recent history of multiple intramuscular injections.

A detailed history with thorough clinical examination along with routine investigations and ultrasonography of pelvic organs was done. History included period of amenorrhea, pelvic and abdominal pain, vaginal bleeding or spotting, vasomotor disturbances like vertigo or syncope. Meticulous physical examination included general physical examination, per abdominal and per vaginal examination. Before any invasive procedure maternal venous samples were collected for CPK, B$\mathrm{HCG}$, in addition to other investigations required for surgical or medical intervention. CPK level was determined by NAC activated with Beckman Coulter AU480.

\section{Statistical analysis}

Data was analysed using the Statistical software namely SAS 9.2, SPSS 15.0 and R environment ver.2.11.1.

\section{RESULTS}

Table 1: Clinical parameters in the studied population.

\begin{tabular}{|llll|}
\hline $\begin{array}{l}\text { Demographic } \\
\text { details }\end{array}$ & $\begin{array}{l}\text { Normal } \\
\text { pregnancy }\end{array}$ & $\begin{array}{l}\text { Abortive } \\
\text { pregnancy }\end{array}$ & $\begin{array}{l}\text { Ectopic } \\
\text { pregnancy }\end{array}$ \\
\hline $\begin{array}{l}\text { Parity } \\
\text { Primi }\end{array}$ & $23(57.5 \%)$ & $19(47.5 \%)$ & $17(42.5 \%)$ \\
\hline Multi & $17(42.5 \%)$ & $21(52.5 \%)$ & $23(57.5 \%)$ \\
\hline Age in years & & & \\
\hline$<20$ & $1(2.5 \%)$ & $0(0 \%)$ & $0(0 \%)$ \\
\hline $20-30$ & $30(75 \%)$ & $31(77.5 \%)$ & $31(77.5 \%)$ \\
\hline $31-40$ & $9(22.5 \%)$ & $9(22.5 \%)$ & $9(22.5 \%)$ \\
\hline Gestational age & & & \\
\hline $3-5$ weeks & $9(22.5 \%)$ & $4(10 \%)$ & $23(57.5 \%)$ \\
\hline $6-10$ weeks & $31(77.5 \%)$ & $33(82.5 \%)$ & $17(42.5 \%)$ \\
\hline$>10$ weeks & $0(0 \%)$ & $3(7.5 \%)$ & $0(0 \%)$ \\
\hline
\end{tabular}

Present study had a total of 120 cases divided into 3 groups; each group consisted of 40 patients each. About $76 \%$ of the pregnant women in the study were between 
20-30 years. But not much difference was found between the Primi and mutligravidas

Table 2: Clinical features of patients who presented with ectopic pregnancy.

\begin{tabular}{|c|c|c|}
\hline $\begin{array}{l}\text { Clinical } \\
\text { presentation }\end{array}$ & $\begin{array}{l}\text { Ectopic } \\
\text { pregnancy }\end{array}$ & $P$ value \\
\hline \multicolumn{3}{|l|}{ Pain abdomen } \\
\hline Absent & $3(7.5 \%)$ & \multirow{2}{*}{$<0.001$} \\
\hline Present & $37(92.5 \%)$ & \\
\hline \multicolumn{3}{|l|}{ Amenorrhoea } \\
\hline Absent & $13(32.5 \%)$ & \multirow{2}{*}{$<0.001$} \\
\hline Present & $27(67.5 \%)$ & \\
\hline \multicolumn{3}{|l|}{ Bleeding P/V } \\
\hline Absent & $28(70 \%)$ & \multirow{2}{*}{$<0.001$} \\
\hline Present & $12(30 \%)$ & \\
\hline \multicolumn{3}{|l|}{ Shock } \\
\hline Absent & $32(80 \%)$ & \multirow{2}{*}{$<0.001$} \\
\hline Present & $8(20 \%)$ & \\
\hline
\end{tabular}

The main complaint which brought the patient to the emergency department was pain abdomen as seen in $92 \%$ of the patients. Whereas a history of amenorrhea was seen only in $67 \%$. Bleeding and shock was seen in 30 and $20 \%$ respectively.

Table 3: CPK distribution in three groups of patients studied.

\begin{tabular}{|llll|}
\hline CPK & $\begin{array}{l}\text { Normal } \\
\text { pregnancy }\end{array}$ & $\begin{array}{l}\text { Abortive } \\
\text { pregnancy }\end{array}$ & $\begin{array}{l}\text { Ectopic } \\
\text { pregnancy }\end{array}$ \\
\hline$<50$ & $37(94.9 \%)$ & $30(75 \%)$ & $0(0 \%)$ \\
\hline $50-100$ & $3(5.1 \%)$ & $10(25 \%)$ & $28(70 \%)$ \\
\hline$>100$ & $0(0 \%)$ & $0(0 \%)$ & $12(30 \%)$ \\
\hline Total & $40(100 \%)$ & $40(100 \%)$ & $40(100 \%)$ \\
\hline
\end{tabular}

$\mathrm{P}<0.001 * *$, Significant, Fisher Exact test

CPK levels were higher in ectopic pregnancy compared to normal and abortive pregnancy.

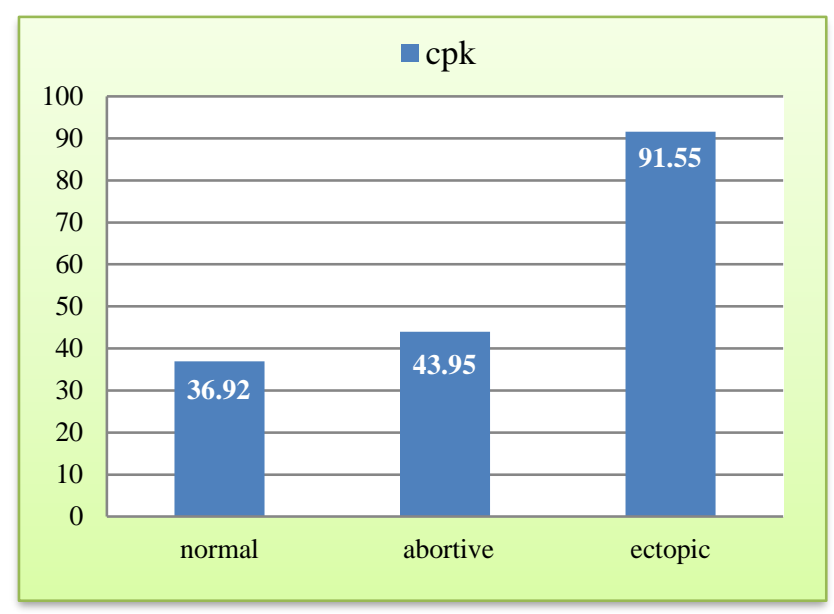

Figure 1: Comparison of mean CPK in three groups of patients studied.
The mean level of CPK was significantly higher in tubal pregnancy compared to other groups $(\mathrm{p}<0.0001)$

Table 4: Management in ectopic surgery.

\begin{tabular}{|lll|}
\hline Management & No. of patients $(\mathbf{n}=\mathbf{4} \mathbf{0})$ & $\%$ \\
\hline Medical Rx & 16 & 40 \\
\hline Laparoscopy & 20 & 50 \\
\hline Laparotomy & 3 & 7.5 \\
\hline D/e & 1 & 2.5 \\
\hline
\end{tabular}

Out of the 40 patients with ectopic pregnancies, 23 presented with rupture, where majority (20) were managed with laparoscopy while 3 underwent laparotomy. 17 unruptured ectopic pregnancies were detected, 16 were managed medically with injection methotrexate while one was a cervical pregnancy which was managed with suction evacuation.

Table 5: CPK levels in relation to ruptured and unruptured ectopic pregnancy.

\begin{tabular}{|llll|}
\hline CPK & \multicolumn{2}{l}{$\begin{array}{l}\text { Ectopic pregnancy } \\
\text { Ruptured }\end{array}$} & $\begin{array}{l}\text { Enruptured } \\
\text { pregnancy }\end{array}$ \\
\hline$<80$ & $4(17.4 \%)$ & $11(64.7 \%)$ & $15(37.5 \%)$ \\
\hline $80-120$ & $15(65.2 \%)$ & $4(23.5 \%)$ & $19(47.5 \%)$ \\
\hline$>120$ & $4(17.4 \%)$ & $2(11.8 \%)$ & $6(15 \%)$ \\
\hline Total & $23(100 \%)$ & $17(100 \%)$ & $40(100 \%)$ \\
\hline
\end{tabular}

Majority of the ruptured ectopic $(65 \%)$ had CPK levels more than 80 while majority of the unruptured $(64 \%)$ had CPK levels less than 80 .

Table 6: Comparison of mean CPK values in relation to ruptured and unruptured in Ectopic pregnancy.

\begin{tabular}{|llll|}
\hline Variables & \multicolumn{2}{l|}{ Ectopic pregnancy } & \multirow{2}{*}{ P value } \\
\hline Mean CPK & $97.26 \pm 25.97$ & $63.82 \pm 34.92$ & 0.015 \\
\hline
\end{tabular}

The mean CPK values were higher in ruptured than in unruptured pregnancies.

\section{DISCUSSION}

Ectopic pregnancy remains a leading cause of maternal mortality and accounts for a sizeable proportion of infertility and ectopic recurrence. ${ }^{8}$ Ectopic pregnancy is still a diagnostic challenge, presenting with various complaints. Though it can be easily treated, early detection is absolutely necessary to prevent fatal consequences. Despite all the advancement $40-50 \%$ of EP is missed at the first assessment. ${ }^{9}$

The present study included a total of 120 women divided into three groups' i.e. normal pregnancy, abortive and ectopic pregnancy, each consisting of 40, majority of the 
women in our study (76\%) were between $20-30$ years of age.

The commonest presenting complaint was abdominal pain $(92.5 \%)$ and period of amenorrhea (67.5\%) which was similar to the results reported by Shetty et al and Porwal et al. ${ }^{10,11}$

In present study, we found the mean CPK in normal, abortive and ectopic pregnancies as 36.92 \pm 6.44 , $43.95 \pm 11.96$ and $91.55 \pm 30.43$ respectively. It is statistically significant $(\mathrm{P}<0.001)$. This is comparable to the Shafi et al study where the mean CPK in ectopic pregnancies was $97.64 \pm 33.08 \mathrm{IU} / \mathrm{L}$ (range 50-350 IU/L) whereas mean CPK in the control group was 53.20 \pm 9.75 IU/L (range 36.2-85 IU/L). ${ }^{12}$ In another similar study by Asgharnia et al where CPK was compared in the similar groups, the mean CPK levels were 96.27 $\pm 63.9 \mathrm{u} / \mathrm{lit}$ (ectopic), 55.37 $\pm 14.1 \mathrm{u} / \mathrm{lit}$ (threatened abortion) and $48.94 \pm 19.2 \mathrm{u} /$ lit (normal pregnancy). ${ }^{13}$

Lavie et al, Chandra et al and Saha et al also found the mean Cpk levels of ectopic pregnancies to be significantly higher than the control groups. ${ }^{4-6}$

In present study, the CPK levels were compared between ruptured and unruptured tubal ectopics and the mean CPK levels in ruptured (97.26 \pm 25.97$)$ were higher than unruptured $(63.82 \pm 34.92)$ which was statistically significant $(\mathrm{p}=0.015)$. However, studies with large study population are required to further validate the findings.

Amina et al in her study also found the CPK levels in ruptured ectopic pregnancies to be higher than unruptured pregnancies. $^{14}$ All the women, with ruptured tubal pregnancy had significant tubal damage and raised values of CPK. This indicates that tubal rupture is associated with an increase in creatine kinase levels, the results are in agreement with the study done by Hala et al. ${ }^{15}$

\section{CONCLUSION}

Ectopic Pregnancy is a common first trimester complication, which can be fatal, if not promptly diagnosed. Hence the need of the hour is a reliable predictor. CPK may serve as an important adjuvant in the diagnosis along with the existing methods of $\beta$-hCG and TVS. In a developing country like India where even in urban areas round the clock USG facilities are not easily available, CPK can be used as a reliable, easily available, rapid and inexpensive biochemical marker for ectopic pregnancy.

Serum CPK has been proved in this study as a valuable measurement for diagnosis of tubal pregnancy and is also useful in discriminating ruptured from unruptured cases. CPK in future can be used in quick diagnosis of ectopic pregnancies thus allowing timely and correct medical or surgical intervention thus preserving future reproductive capability.

\section{ACKNOWLEDGMENTS}

Authors would like to thanks Dr. K. P. Suresh, Scientist (Biostatistics), National Institute of Veterinary Epidemiology and Disease Informatics (NIVEDI), for reviewing the research methodology and statistical results of the study.

Funding: No funding sources

Conflict of interest: None declared

Ethical approval: The study was approved by the Institutional Ethics Committee

\section{REFERENCES}

1. Virkud A. Modern Obstetrics. $2^{\text {nd }}$ ed, APC publishers; chapter 7:63.

2. Cunningham, leveno, Bloom, Williams OBS, $24^{\text {th }}$ ed. Mc graw Hill; chapter 19:377-8.

3. Lott JA, Abott LB. Creatine kinase isoenzyme. Clin Lab Med. 1986;6(3):547-76.

4. Lavie O, Beller U, Neuman M, Ben-Chetrit A, Gottcshalk-Sabag S, Diamant YZ. Maternal serum creatine kinase a possible predictor of tubal pregnancy. Am J Obstet Gynaecol. 1993;169:114950 .

5. Chandra L, Jain A. Maternal serum creatine kinase as a diagnostic marker for tubal pregnancy. Int $\mathbf{J}$ Gynaecol Obstet. 1995;49(1):21-3.

6. Saha PK, Gupta I, Ganguly NK. Evaluation of serum creatine kinase as a diagnostic marker for tubal pregnancy. Aust NZJ Obstet Gynaecol. 1999;39:3667.

7. Kurzel RB, Mazdisnian F, Paige S, Liu P. Serum creatine kinase is not a reliable indicator of ectopic pregnancy. Int J Fertil Women's Med. 2001;46(6):300-3.

8. Chhabra S, Aher K, Jaiswal M. Clinical study of ectopic pregnancy. Indian J Metrn Child health. 1992;3(4):118-21.

9. Houry De, Salhi BA, Acute complications of pregnancy. In: Marx JA, ed. Rosen's Emergency Medicine: Concepts and Clinical Practice. 7th ed. Philadelphia, Pa: Mosby Elsevier; 2009:176.

10. Shetty S, Shetty A. A clinical Study of Ectopic Pregnancies in a Tertiary care hospital of Mangalore, India. Innovative J Med Health Sci. 2014;4(1):305-9.

11. Gupta R, Porwal S, Swarnkar M, Sharma N, Maheshwari P. Incidence, trends and risk factors for Ectopic Pregnancies in a tertiary care hospital of Rajasthan. JPBMS. 2012;16(16):16.

12. Shafi S, Beigh M, Jan S. Reliability of maternal serum creatine kinase in diagnosis of tubal pregnancy. IOSR-JDMS. 2016;15(4):26-31.

13. Maryam, Faraji R, MIrblouk F, Roshan ZA, Parvizi A. Evaluation of serum creatine phosphokinase in diagnostic of tubal ectopic pregnancy compared with intrauterine pregnancy and threatened abortion. Iran J Reprod Med. 2012;10(4):303-6. 
14. Mohammad AA, Ahmad HF, Effat DM, El-sayed Z. The role of creatine phosphokinase and B-hcg in the early diagnosis of ectopic pregnancy. Nat Sci. 2012;10(11):225-30.

15. Abdullateef HA. serum creatine kinase and its isoenzymes $\mathrm{CK}-\mathrm{MB}$ in the prediction of tubal ectopic pregnancy. Iraqi J Med Sci. 2013;11(2):1705.

Cite this article as: Ganta SJ, Kulkarni SR,

Muralidhar V. CPK: The new tool in the diagnosis of ectopic pregnancy. Int J Reprod Contracept Obstet Gynecol 2017;6:2507-11. 